\title{
Stigma among HIV/AIDS patients in China
}

\author{
Wah Fung Tse, Wenlong Huang \\ China Pharmaceutical University
}

\begin{abstract}
Introduction: HIV-related discrimination swept the globe accompanied by the HIV/AIDS virus. Patients with acquired immune deficiency syndrome (AIDS) are discriminated because they are linked to whoring, drug abuse, sexual behaviour - men who have sex with men (MSM), and sexual promiscuity worldwide. AIDS has been discriminated as a result of being considered as a "gay plague" followed by the AIDS epidemic for a long period. In recent years, it is been getting worse in China. Aim of the study was to realise the current status of HIV-related stigma and discrimination and its research in China by literature retrieval.
\end{abstract}

Material and methods: We searched databases including PubMed, Elsevier, CNKI, WangFang Data, and VIP from 2005 to May 2016, to identify studies involving discrimination against HIV/AIDS patients.

Results: On the whole, discrimination against people living with HIV and AIDS mainly comes from inner discrimination and external discrimination. Inner discrimination includes self-discrimination and perceived discrimination, and external discrimination is mainly from five fields: medical and reproductive health, school, work and housing, passive and physical harassment of HIV and their family members, and violation of rights and health treatment.

Conclusions: Although there has been remarkable progress in the prevention and treatment of HIV/ AIDS in China, HIV-related stigma and discrimination remain enormous barriers to effectively fighting the HIV and AIDS epidemic. The discrimination can be relieved from three aspects including amending certain laws and regulations, strengthening the training of health personnel, and reinforcing dissemination of information related to HIV/AIDS.

HIV AIDS Rev 2017; 16: 11-17 DOI: https://doi.org/10.5114/hivar.2017.65921

Key words: HIV, AIDS, stigma, discrimination, China.

\section{Introduction}

Since the first case of acquired immune deficiency syndrome (AIDS) diagnosed in the United States in 1981, more than 33 million people worldwide have been infected with human immunodeficiency virus (HIV) [1]. The global epidemic is a global emergency and one of the most formidable challenges to life and dignity, to the enjoyment of human rights, and to economic development [2]. As reported by the National Centre for AIDS/STD Control and Prevention of China CDC in November 2015, it was estimated that people living with HIV and AIDS (PLWHA) account for 0.06\% of the total population in China, which means 6 persons in 10,000 are infected with the AIDS virus. By the end of October 2015, there were a total of 575,000 people living with HIV and AIDS in China, and 177,000 AIDS-related deaths.

According to the 2014 China AIDS control and treatment progress report released by the Nation Health and Family Planning Commission of People's Republic of China,
Address for correspondence: Prof. Wenlong Huang, China Pharmaceutical University, Longmian Road 639, 211198 Nanjing, China, e-mail: wahfungtse@163.com
Article history:

Received: 11.08 .2016

Received in revised form: 03.10.2016

Accepted: 01.11.2016

Available online: 09.02.2017
International Journal of HIV-Related Problems

HIV \& AIDS

R e vi e w 
the Chinese AIDS epidemic mainly presents four characteristics:

1. Low morbidity of AIDS in China, high morbidity in particular areas and population.

According to a national report, people living with HIV and AIDS accounted for $0.033 \%$ of the total population in China by the end of 2013. Although there are some HIV infected people who have not yet been found, the national AIDS situation still has a low prevalence overall.

2. The reported number of people living with HIV and AIDS alive increased continuously, and the AIDS morbidity in different populations shows a huge difference.

In 2009-2013, the number of people living with HIV and AIDS increased continuously: respectively, 272,000, $307,000,352,000,386,000$, and 437,000. The main reasons for the increased number of people alive include the following two aspects: on one hand, patients tested for HIV infection increased year by year, so that the annual number of newly diagnosed people infected with HIV and AIDS increased year by year; on the other hand, there was a significant increase in the number of newly added patients receiving treatment annually, so that more patients' lives were prolonged.

3. The significantly rising number of AIDS patients and all-cause deaths.

Report showed that the number of AIDS patients alive in China was, respectively, 74,000, 96,000, 121,000, 146,000, and 174,000 in 2009-2013, and the number of all-cause deaths of PLWHA, respectively, was 12,000, 19,000, 21,000, 23,000 , and 22,000. There are two factors causing increased mortality. First, the proportion of PLWHA alive into the clinical stage will increase with disease progression. Second, as the age of the survivors naturally grows and the proportion of aged patients among newly diagnosed patients increases each year, the proportion of the aged group alive is rising.

4. Sexual transmission is the main way of transmitting HIV; men who have sex with men (MSM) transmission increased significantly.

In reports over the years, the constituent ratio of MSM and heterosexual transmission showed a rising trend year by year. In newly discovered cases, the proportion of sexual transmission increased per year from $33.1 \%$ in 2006 to $90.8 \%$ in 2013, and the proportion of MSM transmission increased from $2.5 \%$ in 2006 to $21.4 \%$ in 2013 .

HIV-related discrimination swept the globe accompanied by the HIV/AIDS virus. AIDS patients are discriminated because they are linked to prostitution, drug abuse, MSM, and sexual promiscuity worldwide. AIDS, originally named "gay immunodeficiency disease" in the United States, has been discriminated as a result of being considered as a "gay plague" followed by the AIDS epidemic for a long period [3].

This study will complete narrative reviews by searching Chinese and English literature to understand current situation of Chinese HIV-related discrimination and research.

\section{Material and methods}

We searched Chinese databases including CNKI, WangFang Data, and VIP with the search words "AIDS", "discrimination", and "stigma", and the retrieval strategy is "AIDS" and "discrimination or stigma" with the publication data from 2005 to May 2016.

We searched English databases including Pubmed and Elsevier with the search words "China", "AIDS/HIV", "Stigma", and "Discrimination". The retrieval strategy was as follows: \#1. China[Title/Abstract] \#2. AIDS[Title/Abstract]) or HIV[Title/Abstract] \#3. Stigma[Title/Abstract]) or discrimination[Title/Abstract] \#4. “2005”[Date - Publication]: “2016” [Date - Publication] \#1 AND \#2 AND \#3 AND \#4

\section{Results}

According to the search results, scholars have done a great deal of research about discrimination or stigma of people living with HIV and AIDS (PLWHA). On the whole, discrimination against people living with HIV and AIDS mainly comes from inner discrimination and external discrimination. Inner discrimination includes self-discrimination and perceived discrimination, and external discrimination is mainly from five fields: medical and reproductive health, school, work and housing, passive and physical harassment of HIV and their family members, and violation of rights and health treatment. In addition, the actuality research and counter matter study are also important contents.

\section{Inner discrimination}

From the perspective of people living with HIV and AIDS, inner discrimination can divided into two types. One is self-discrimination, referring to the decrease of selfworth, negative self-cognition, and inner shame. The other is perceived stigma, referring to others' attitudes and the actions of people living with HIV and AIDS [4].

The China Stigma Index Report, reported by the Joint United Nations Programme on HIV and AIDS (UNAIDS) and the Ministry of Health in China in 2009, is based on the results of the China stigma survey of people living with HIV and AIDS. More than 2000 people living with HIV and AIDS participated in this survey. Self-stigma is a common problem for people living with HIV and this was clearly reflected in the survey results. Almost two out of three $(62.1 \%)$ respondents reported that they had felt ashamed and $43.2 \%$ said they had felt guilty about their HIV status. Almost three quarters blamed themselves (74.5\%) or had low self-esteem (75.4\%). Over 50\% of women and over $40 \%$ of men had considered suicide since being infected. Self-stigma had also led respondents to taking or avoid taking various types of action. For example, more than half $(60.8 \%)$ of those aged between 15 and 50 years said that they had decided not to have children as a result of being HIV positive, $34.7 \%$ of those of working 
age had decided to stop working, and over 55\% had chosen not to attend social gatherings $(55.4 \%)$ or had isolated themselves from family and friends (58.1\%). Huang Wei (2016) surveyed 144 HIV/AIDS patients in Wuhan city and Suizhou city with the Berger HIV Stigma Scale to measure the state of perceived stigma among MSM and paid blood donors with HIV/AIDS (PBDHA). The results showed that the level of perceived stigma differs with the type of HIV/ AIDS patients and their individual status, and the score of perceived stigma in the MSM population is higher than in the PBDHA population [5].

\section{External discrimination}

\section{Medical and reproductive health}

The China Stigma Index Report indicated that 12.1\% of respondents had been refused medical care at least once since they tested positive. Thirty-two respondents (1.7\%) said they had been refused family planning services, and 28 respondents $(1.5 \%)$ had been refused reproductive health services since being diagnosed as HIV positive. In addition, a survey conducted by Jiang Hongying (2010) of 48 people with HIV/AIDS showed that all of the 48 HIV/AIDS patients experienced discrimination from healthcare workers. Twenty-three patients agreed that discrimination still existed even in designated HIV/AIDS hospitals. An investigator was not allowed to register for a doctor when she pretended to be a pregnant woman infected with HIV. It sometimes happened that pregnant women infected with HIV were refused by hospitals [6].

In the research of Zhang Yuan (2011), a cross-sectional self-administered questionnaire survey was conducted among 392 doctors and nurses from two general hospitals in Beijing to ascertain health personnel's attitudes towards people living with HIV/AIDS. The result showed that PLWHA were strongly discriminated by health personnel. The attitude of health personnel to PLWHA is disgust and blame, fear and overreaction, and refusal to provide healthcare. $81.5 \%$ of respondents were disgusted with PLWHA infected through sexual transmission, and $45.8 \%$ of them were very disgusted. About $90.7 \%$ of respondents considered that the risk of being infected existed in the healthcare process. Half of the interviewed health personnel (53.4\%) thought that they should have the right to refuse to provide healthcare services, while only $16.6 \%$ were opposed to this idea. $90.0 \%$ of respondents agreed that it was necessary to go to the designated hospitals of HIV/AIDS for PLWHA. On the whole, the attitude of health personnel to PLWHA is negative. The moral blame, the fear of PLWHA, and the lower willingness of service are common among health personnel [7]. PLWHA suffer very much due to discrimination from Medical and Reproductive Health workers in China. The discrimination from medical and reproductive health workers has a negative impact on the testing and treatment of HIV/AIDS in the public, which hinders the improvement of work against HIV/AIDS.
The causes of discrimination in the medical area mainly include moral evaluation, disease condition, and hospital training. As for the moral evaluation, Zhang Yuan (2011) pointed out the influence of moral labelling on HIV/AIDS discrimination [7]. Zhang Liping (2011) also indicated that health personnel may evaluate PLWHA according to morality [8]. As for the disease condition, although health personnel possess more medical knowledge, they still fear HIV/ AIDS. The clinical manifestations and prognosis may result in fear of PLWHA and discrimination [9]. As for the hospital training, Zhang Liping (2011) indicated that the fear of infection after occupational exposure is the main reason for discrimination. Meanwhile, most hospitals lack the training of occupational exposure in detail, and the doctors who have close contact with PLWHA have not received comprehensive training. These causes may lead to the discrimination [8].

\section{School, work, and housing}

As a very strong expression of stigma and discrimination, a significant proportion of PLHIV reported having lost their job, having been forced to leave school or move out of their home, or even having found that their family members experienced discrimination in various forms, as a result of their HIV status. Since being diagnosed with HIV 277 respondents ( $14.8 \%$ of a total of 1877 respondents) said they had been refused employment or a work opportunity because of their HIV status (16.3\% for men and 13\% for women). Another 305 (16.8\%) reported that their job or nature of work changed, and 70 respondents $(3.8 \%)$ said they had been denied a promotion because of their HIV status. Sun Shidong (2016) conducted a cross-sectional survey in which $2432 \mathrm{HIV}$-positive cases and AIDS patients from seven provinces were interviewed about their past experiences when seeking jobs or being at work. The result showed that $42.1 \%$ reported having experienced employment-related discrimination among interviewers [10]. All these figures show that employment-related discrimination exists in China.

In addition to employment-related discrimination, PLWHA also suffer from discrimination in terms of education. In the China Stigma Index Report, 9.1\% of those with children said that their children, although not necessarily HIV positive themselves, had been forced to leave school because of the HIV status of their parents. Of the 113 respondents aged under 25 years, who would be most likely to be in education, $6.2 \%$ said they had been forced to leave school on at least one occasion as a result of their HIV status. As noted above, $36.2 \%$ of respondents said that teachers had shown a "discriminatory" or "very discriminatory" attitude upon learning of their HIV status.

In other research, $95.9 \%$ of parents reached an agreement that students with HIV/AIDS had the right to education, but if there was an HIV infected student in their children's class, $14.1 \%$ of parents demanded that the infected student be transferred to another school or class, $5.9 \%$ of parents demanded their own children be transferred to another school or class, $11.8 \%$ parents thought that a separate seat in the last 
row should be prepared for the HIV/AIDS infected student, and $43.0 \%$ parents had no demands but warned their children not to have contact with the infected child. According to the answers of students, $39.8 \%$ of students avoided contact with the HIV infected classmate, $6.8 \%$ expected the infected classmate to transfer to another school or class, nearly $8 \%$ of children wanted to change class or school, and $12.4 \%$ students thought that a separate seat in the last row should be prepared for the HIV/AIDS infected student [11].

The China Stigma Index Report also concerns housing. Of the 1892 respondents who answered the question on accommodation, $7.1 \%$ (134 respondents) had, on at least one occasion since being diagnosed with HIV, been forced to move residence or had been unable to find accommodation because of their HIV status.

These figures show that discrimination in vital areas such as employment, education, and housing is significant. The main causes include bigotry and misunderstanding among the public and the imperfection of the legal system against AIDS discrimination. As in the discrimination in the medical area, bigotry and misunderstanding are also common in daily life. People are afraid of PLWHA in consideration of their probable behaviour and potential infection. A lack of AIDS knowledge can result in public bigotry. Public knowledge of AIDS is insufficient to build up their confidence to prevent transmission of HIV, so the majority of people worry about being infected. The public acquire knowledge mainly from magazines, newspaper, websites, radio, and television, which play a vital role in popularising knowledge of AIDS. However, the knowledge acquired in these ways is not systematic enough.

Regarding the legal system, the current position against AIDS discrimination is imperfect. For instance, there is no clear definition of employment and occupational discrimination and the regulation of legal liability, and the scope of application is not wide enough to involve informal employment and migrant workers, and the content of employment and occupational discrimination is incomplete. In consequence, the law enforcement and supervision is short of evidence. Huang Jinyi (2014) clearly indicated that current anti-discrimination about AIDS is almost reflected in administrative regulations and department rules and does not reach the level of basic law, which makes the legal force of anti-discrimination about AIDS weak and non-systematic. Furthermore, there are some negative regulations involving AIDS discrimination and violating the constitution's promise of equality, such as the General Standard of Physical Examination for Civil Servant Employment [12].

\section{Passive and physical harassment of PLHIV and their family members}

Discrimination and stigma are also experienced in the form of passive and physical harassment of PLWHA and their family members in the China Stigma Index Report. While not many respondents had experienced actual physical attacks, many had noticed others gossiping about them, a clear form of social discrimination. Almost one in five had been verbally insulted or threatened, clearly demonstrating the lack of acceptance of people living with HIV by mainstream society. Women suffered from discrimination more often than men. For example, 725 respondents (38.8\%) had been aware of being gossiped about on at least one occasion because of their HIV status. The proportions were $34.5 \%$ for men and $47.6 \%$ for women. Of all survey respondents, more than $76 \%$ said that their family members had experienced discrimination as a result of their HIV status.

\section{Violation of rights}

Rights violations may occur in many ways, especially among marginalised populations, who are often less protected and less empowered in society. Discrimination and rights violations experienced by respondents because of their HIV positive status were noticeable and distinctive. Of the 1707 people who answered the question in the China Stigma Index Report, more than $20 \%$ had experienced violations of their individual rights since being diagnosed with HIV, as a result of their HIV status. In general, the proportion of women who had experienced rights violations was higher than the proportion of men. The rights violations experienced by respondents involved being forced to take HIV tests during a medical examination, being denied health/life insurance, being forced to submit medical/health reports, and being detained, quarantined, or ostracised.

Of the respondents who had experienced rights violations, 110 respondents (31.2\%) had tried to seek redress. Of those who chose not to take any action against a violation of their rights, the primary reason given was a lack of faith in the possibility of success. This lack of faith in the possibility of success seems to be based on a solid reality: of those that had sought redress for a violation of their rights, only $19.8 \%$ had been successful in their action, while for $68.3 \%$ the matter had still not been resolved. $37.8 \%$ of people who had had their rights violated had sought help from government employees to obtain redress. Of those people, $15.8 \%$ had had the matter resolved.

\section{Health and treatment}

Antiretroviral treatment results in improvements in the general health and quality of life of PLWHA. Increased coverage of ART has led to a large reduction in HIV-associated morbidity and mortality globally. The China Stigma Index Report shows that $62.9 \%$ of respondents said they were currently on antiretroviral treatment (females 68.6\%, males 60.2\%), but of concern are the $2.9 \%$ of respondents not currently taking antiretroviral treatment, citing cost as the reason. Of the 171 female respondents who were HIV positive at the time of their pregnancy, only 40 women (23.4\%) received antiretroviral treatment to prevent mother-to-child transmission. The result of this survey indicates that the coverage of antiretroviral treatment was high among the people participating in the survey, while there seem to be significant problems with antiretroviral treatment to prevent mother-to-child transmission (MTCT), and coverage is low. According to other research (Yan Min, 
Table 1. The main information of research

\begin{tabular}{|c|c|c|c|c|}
\hline Name & Method & Site & Discrimination type & Main content \\
\hline $\begin{array}{l}\text { The China } \\
\text { Stigma Index } \\
\text { Report }\end{array}$ & $\begin{array}{l}\text { Questionnaire } \\
\text { survey; } \\
\text { interview survey }\end{array}$ & $\begin{array}{l}25 \text { (provinces, } \\
\text { municipalities, and } \\
\text { autonomous regions) }\end{array}$ & $\begin{array}{l}\text { Inner discrimination; } \\
\text { external } \\
\text { discrimination }\end{array}$ & $\begin{array}{l}\text { Self-discrimination; } \\
\text { external discrimination } \\
\text { (medical and reproductive health, } \\
\text { school, work, and housing, passive } \\
\text { and physical harassment, violation } \\
\text { of rights, health, and treatment) }\end{array}$ \\
\hline $\begin{array}{l}\text { Huang Wei } \\
(2016)\end{array}$ & $\begin{array}{l}\text { Questionnaire } \\
\text { survey }\end{array}$ & Wuhan, Suizhou & Inner discrimination & $\begin{array}{c}\text { The state of perceived stigma among } \\
\text { MSM and paid blood donor } \\
\text { with HIV/AIDS (PBDHA) }\end{array}$ \\
\hline $\begin{array}{l}\text { Jiang Hongying } \\
(2010)\end{array}$ & $\begin{array}{l}\text { Interview survey; } \\
\text { role play }\end{array}$ & Nanchang & $\begin{array}{c}\text { Inner discrimination; } \\
\text { external } \\
\text { discrimination }\end{array}$ & $\begin{array}{c}\text { Self-discrimination; } \\
\text { discrimination in medical field }\end{array}$ \\
\hline $\begin{array}{l}\text { Zhang Yuan } \\
\text { (2011) }\end{array}$ & $\begin{array}{l}\text { Questionnaire } \\
\text { survey }\end{array}$ & Beijing & $\begin{array}{c}\text { External } \\
\text { discrimination }\end{array}$ & Discrimination from health personnel \\
\hline $\begin{array}{l}\text { Zhang Liping } \\
(2011)\end{array}$ & Literature review & - & $\begin{array}{l}\text { Inner discrimination; } \\
\text { external } \\
\text { discrimination }\end{array}$ & $\begin{array}{l}\text { The actuality and causes } \\
\text { of discrimination against AIDS/HIV }\end{array}$ \\
\hline $\begin{array}{l}\text { Sun Shidong } \\
(2016)\end{array}$ & $\begin{array}{l}\text { Questionnaire } \\
\text { survey }\end{array}$ & 7 provinces & $\begin{array}{c}\text { External } \\
\text { discrimination }\end{array}$ & $\begin{array}{l}\text { Employment related discrimination } \\
\text { experienced by HIV/AIDS cases }\end{array}$ \\
\hline $\begin{array}{l}\text { Ding Suqin } \\
(2007)\end{array}$ & $\begin{array}{l}\text { Questionnaire } \\
\text { survey }\end{array}$ & Harbin & $\begin{array}{c}\text { External } \\
\text { discrimination }\end{array}$ & $\begin{array}{c}\text { The right of schooling of AIDS orphans } \\
\text { and vulnerable children (OVC) }\end{array}$ \\
\hline $\begin{array}{l}\text { Huang Jinyi } \\
(2014)\end{array}$ & Literature review & - & $\begin{array}{c}\text { External } \\
\text { discrimination }\end{array}$ & $\begin{array}{l}\text { The types of discrimination } \\
\text { and legal system research }\end{array}$ \\
\hline Yan Min (2016) & $\begin{array}{l}\text { Interview survey; } \\
\text { group discussion }\end{array}$ & $\begin{array}{c}\text { A county in } \\
\text { Liangshan prefecture }\end{array}$ & $\begin{array}{c}\text { External } \\
\text { discrimination }\end{array}$ & $\begin{array}{l}\text { The causes of non-treatment } \\
\text { of migrant workers with HIV/AIDS }\end{array}$ \\
\hline $\begin{array}{l}\text { Nie Junxiong } \\
(2010)\end{array}$ & - & - & - & $\begin{array}{c}\text { The discrimination against HIV/AIDS } \\
\text { and anti-discrimination policy }\end{array}$ \\
\hline $\begin{array}{l}\text { Shi Chaoming } \\
(2012)\end{array}$ & - & - & - & $\begin{array}{l}\text { The difficulties and countermeasures } \\
\text { of anti-discrimination }\end{array}$ \\
\hline $\begin{array}{l}\text { Yan Limeng } \\
(2015)\end{array}$ & $\begin{array}{l}\text { Questionnaire } \\
\text { survey }\end{array}$ & Shanghai & $\begin{array}{c}\text { External } \\
\text { discrimination }\end{array}$ & $\begin{array}{l}\text { The status about the social } \\
\text { discrimination against AIDS } \\
\text { in Shanghai, and suggestions for } \\
\text { the policy formulation and adjustment }\end{array}$ \\
\hline
\end{tabular}

- means no relevant information

2016) analysing the causes of non-treatment of migrant workers with HIV/AIDS in a county in Liangshan Prefecture, discrimination and stigma of AIDS contributes to the non-treatment of some PLWHA. The antiretroviral treatment may increase the chance of their HIV status being exposed. A number of patients would rather give up the treatment in case of being discriminated against by others [13].

\section{Counter matter study}

A number of scholars put forward solutions and countermeasures for the actuality of AIDS discrimination. Nie Junxiong (2010) thought that the anti-discrimination has a long way to go, which includes promoting the feasibility of antidiscrimination legislation, strengthening propaganda and policy direction for the general public, implementing related responsibilities, enhancing the construction of medical ethics and ethos, cultivating medical staff with medical humanities, and so forth [14]. In the study by Shi Chaoming (2012), the forms of AIDS discrimination and measures of eliminating AIDS discrimination in China are introduced. Considering the difficulties of eliminating China's anti-AIDS discrimination, the author puts forward suggestions to eliminate AIDS discrimination [15]. Moreover, Yan Limeng (2015) makes suggestions for policy formulation and adjustment based on the status of the social discrimination against AIDS in Shanghai from the investigation of 1737 people. The implementation of AIDS prevention and control could be carried out through five aspects, including anti-discriminatory legal assistance, the prevention of HIV/AIDS, policy promotion and advocacy, promotion of prevention knowledge, and education about anti-discrimination [16].

The following chart is about the main research mentioned above. 


\section{Discussion}

According to the Global Health Sector Strategy on HIV, 2016-2021, the HIV strategy contains three organising frameworks: universal health coverage, the continuum of health services, and the public health approach. Universal health coverage is achieved when all people receive the health services required, which are of sufficient quality to make a difference, without those people incurring financial hardship. As for the continuum of health services, countries need to implement high impact, evidence-based interventions along the entirety of the continuum of services for HIV vulnerability and risk reduction, prevention, diagnosis, treatment, and chronic care. A public health approach aims to achieve health equity and promote gender equality, to engage communities, and to leverage public and private sectors in the response.

Faced with the challenge of AIDS/HIV in China, many United Nations agencies, Chinese government departments, and non-governmental organisation departments engaged in AIDS prevention and control have continuously focused on discrimination issues relating to AIDS and have made good progress in policy advocacy and publicity. As for policy, since 2004 the central government and local government have issued or revised some laws, regulations, and measures against AIDS discrimination to protect infected persons' legitimate rights and interests in employment, medical care, insurance, and other aspects. For example, in January 2006 the State Council promulgated the "AIDS prevention and control regulations". The third rule of the first chapter in the regulations stipulates that "any unit or individuals shall not discriminate against persons infected with HIV, AIDS patients, and their families. PLWHA and their families' legitimate rights and interests of marriage, employment, medical care, and schooling are protected by law". "The employment promotion law of the People's Republic of China" was adopted by the $29^{\text {th }}$ meeting of the $10^{\text {th }}$ National People's Congress standing committee on August 30, 2007. The thirtieth rule of this law stipulates that employers shall not refuse to employ, citing a reason of disease pathogen carriers. As for publicity, government departments, agencies, and nongovernmental organisations at all levels carried out various forms of AIDS campaigns within the past five years, such as formulating work guidelines and knowledge points about publicity of prevention and control of AIDS.

Although China has made much progress in anti-discrimination, it is a long and difficult process to eliminate stigma and discrimination against PLWHA in public attitudes, beliefs, and behaviours, and to change or cancel discriminatory clause of the laws, regulations, and policies. In China, there are some problems in anti-discrimination, for example the following:

1. The public awareness of AIDS is not deep enough.

2. Fear and ignorance of AIDS from grassroots medical workers leads to medical discrimination.

3. Relevant legislation to protect PLWHA remains weak.

4. Lack of supervision and safeguard mechanisms about AIDS-related policies and regulations.
5. Weak legal awareness of infected persons, the high cost of rights protection, and the lack of legal aid agencies.

Based on the current situation of discrimination against PLWHA, as well as the analysis of the existing problems, we put forward the following suggestions for anti-discrimination work in the future:

1. Sensor and revise relevant laws and regulations, strengthen the protection of legislation for PLWHA.

Anti-discrimination clauses of laws and regulations of "Infectious diseases prevention law" and the "AIDS Prevention Act" are mainly based on the principle, but the detailed operating rules are not clear. These laws and regulations ignored the rights and interests of PLWHA and failed to give them appropriate protection [17]. Local governments can formulate and implement the relevant detailed rules and refine the relevant content in the consideration of the status of vulnerable groups of PLWHA to enhance the operability in protection for their legitimate rights and interests.

2. The Health Administrative Departments should strengthen the formulation, implementation, and supervision of anti-discrimination policy, while strengthening the training of medical personnel.

Health administrative departments should strengthen the formulation, implementation, and supervision of anti-discrimination policies, and create a better environment for medical treatment for PLWHA from the system. Studies have shown that occupational exposure is one of the underlying causes of discrimination [18]. Medical personnel in community health service institutions working at the forefront of providing health services have a higher risk of occupational exposure, and a lack of knowledge and skills to handle the exposure and standard precautions training [19]. Therefore, it is necessary to establish a scientific management of the medical environment and build standardised and specific post-exposure emergency measures to improve occupational protection measures and reduce the fear, discrimination, and occupational exposure. In addition, hospitals should improve medical ethics construction, strengthen professional ethics education for the medical personnel, and standardise behaviour of treatment and diagnosis for PLWHA. Furthermore, medical personnel should clearly realise the specified responsibilities and obligations to treat PLWHA and exhibit good medical morality and conscience in the treatment process [20].

3. Strengthen the publicity of AIDS.

Government and social organisations should improve the level and depth of content of publicity, and should popularise relevant immune knowledge in the process of publicity in the future because a lot of discrimination against HIV/ AIDS stems from a lack of knowledge about AIDS. For example, government and social organisations should actively give play to the guiding role of the mass media through the Internet, newspapers, television, radio, and other media to improve concern and care for HIV-infected persons, and guide people to establish a correct and scientific understanding to practically protect their rights and interests through 
objective, real, and positive coverage of relevant information about HIV/AIDS.

\section{Conclusions}

The influence of HIV-related social discrimination on PLWHA has never been terminated. PLWHA not only suffer from the torture of the disease itself, but also bear great social and economic pressure, which can even affect their friends, families, communities, and the entire country.

Currently, HIV-related discrimination is still a great social challenge for PLWHA in all aspects of healthcare, employment, education, and housing. The discrimination not only infringes their rights and interests, but also prevents the provision of timely HIV prevention, treatment, and care services, which makes it very difficult to control the AIDS epidemic. In recent years, although there has been remarkable progress in the prevention and treatment of HIV/AIDS in China, HIV-related stigma and discrimination remain enormous barriers to effectively fighting the HIV and AIDS epidemic. The discrimination can be relieved from three aspects: amending certain laws and regulations, strengthening the training of health personnel, and reinforcing dissemination of information regarding HIV/AIDS.

\section{Conflict of interest}

The author's declared no potential conflicts of interest with respect to the research, authorship, and/or publication of this article.

\section{References}

1. Petros P. Risk perception, HIV/AIDS related knowledge, attitude and practice of the university community: The case of Ethiopian Civil Service College. HIV AIDS Rev 2014; 13: 26-32.

2. UNAIDS. Keeping the promise: summary of the Declaration of Commitment on HIV/AIDS, 2002.

3. Zhang Y. Stigma and HIV discourse in China. J Soc Sci 2011.

4. Xian-Hong LI, Guo-Ping HE, Wang HH. Concept and Measurement of HIV/AIDS Related Stigma and Discrimination. Adv Psychol Sci 2009.

5. Huang Wei, Cai Juan-li, Shi Wei-dong, et al. Perceived stigma among 144 patients with HIV/AIDS. Moderen Prevention Medicine 2016; 43.

6. Jiang HY, Jun FU, Liu JH. Qualitative study of AIDS-related discrimination among the people with HIV/AIDS. Modern Preventive Medicine 2010.

7. Zhang Y, Niu WY. The Attitudes and Its Influential Factors of Health Personnel Towards People Living with HIV/AIDS: An Example of two General Hospitals in Beijing. Medicine \& Philosophy 2011.

8. Zhang LP, Peng XU, Fan LV. Study on current situation of discrimination against HIV/AIDS in China and related strategic suggestions. Chinese Journal of AIDS \& Std. 2011.

9. Herek GM, Glunt EK. An epidemic of stigma. Public reactions to AIDS. Am Psychol 1988; 43: 886-891.

10. Sun Shi-dong, Xu Peng, et al. Prevalence and associated factors of employment related discrimination experienced by HIV/AIDS cases. Practical Preventive Medicine 2016.
11. Ding SQ, Ying-Hua MA, Wang C. The anti-discrimination attitudes of 620 students towards the right of schooling of AIDS orphans and vulnerable children (OVC) and the influential factors. Modern Preventive Medicine 2007.

12. Huang JY, University S. Research on the Legal System of Antidiscrimination about AIDS. Academic Journal of Shanxi Provincial Committee Party School of C.p.c. 2014.

13. Yan Min, Dazheng Ci-ji, Zeng Can, et al. Qualitative analysis of the causes of non - treatment of migrant workers with HIV/ AIDS in a county in Liangshan Prefecture. Modern Prevention Medicine 2016

14. Nie JX, Wang R. On the discrimination against HIV/AIDS carriers and anti-discrimination policy. Chinese Medical Ethics 2010.

15. Shi C. Difficulties, Dilemma and Countermeasures: There is a Quite Long Way Ahead for China's Anti-AIDS Discrimination. Medicine \& Society 2012.

16. Yan Li-meng, Wang Yan-ting. Evaluation and suggestion on social discrimination against AIDS and interventional policy in Shanghai. Journal of Public Health and Preventive Medicine 2015; 26: 47-50.

17. He Li. The Thinking of related HIV/AIDS Legislation. Think Tank 2009; 4: 79-85.

18. Liu J, Zhu L, Han LF. The Risk Factors of the Medical Staff Occupational Exposure to AIDS Assess and Investigation into the Protection Status. Chinese Hospital Management. 2010.

19. Xu Peng, Han Lin, Zeng Gang, et al. Analysis of Health Care Workers' Knowledge and Attitude About HIV/AIDS Related Occupational Exposure. Chinese Hospital Management 2014; 34: 66-69.

20. Li-Ping MA, Peng XU, Fu-Chang MA. Survey on awareness of HIV knowledge,discriminative attitudes and related influencing factors of workers related to HIV/AIDS prevention practice in community health service centers. Chinese Journal of AIDS \& Std. 2014. 